\title{
E-cigarette use and associated changes in population smoking cessation: evidence from US current population surveys
}

\author{
Shu-Hong Zhu, ${ }^{1,2}$ Yue-Lin Zhuang, ${ }^{2}$ Shiushing Wong, ${ }^{2}$ Sharon E Cummins, ${ }^{1,2}$ Gary J Tedeschi ${ }^{2}$
}

${ }^{1}$ Department of Family Medicine and Public Health, University of California, San Diego, 9500 Gilman Drive MC 0905, La Jolla, CA 92093-0905, USA

${ }^{2}$ Moores Cancer Center, University of California,

San Diego, CA, USA

Correspondence to: S-H Zhu

szhu@ucsd.edu

Cite this as: $B M$ J 2017;358:j3262 http://dx.doi.org/10.1136/bmj.j3262

Accepted: 04 July 2017

\section{ABSTRACT}

OBJECTIVE

To examine whether the increase in use of electronic cigarettes in the USA, which became noticeable around 2010 and increased dramatically by 2014, was associated with a change in overall smoking cessation rate at the population level.

\section{DESIGN}

Population surveys with nationally representative samples.

\section{SETTING}

Five of the US Current Population Survey-Tobacco Use Supplement (CPS-TUS) in 2001-02, 2003, 2006-07, 2010-11, and 2014-15.

\section{PARTICIPANTS}

Data on e-cigarette use were obtained from the total sample of the 2014-15 CPS-TUS ( $n=161054)$. Smoking cessation rates were obtained from those who reported smoking cigarettes 12 months before the survey $(n=23270)$. Rates from 2014-15 CPS-TUS were then compared with those from 2010-11 CPSTUS $(n=27280)$ and those from three other previous surveys.

\section{MAIN OUTCOME MEASURES}

Rate of attempt to quit cigarette smoking and the rate of successfully quitting smoking, defined as having quit smoking for at least three months.

RESULTS

Of 161054 respondents to the 2014-15 survey, 22548 were current smokers and 2136 recent quitters. Among them, $38.2 \%$ of current smokers and $49.3 \%$ of recent quitters had tried e-cigarettes, and $11.5 \%$ and $19.0 \%$ used them currently (every day or some days). E-cigarette users were more likely than non-users to attempt to quit smoking, $65.1 \%$ v $40.1 \%$ (change $=25.0 \%, 95 \%$ confidence interval $23.2 \%$ to $26.9 \%)$, and more likely to succeed in quitting, $8.2 \%$ v $4.8 \%$ (3.5\%, $2.5 \%$ to $4.5 \%)$. The overall population

\section{WHAT IS ALREADY KNOWN ON THIS TOPIC}

Researchers have offered competing hypotheses about whether the dramatic increase in e-cigarette use helps or hinders smoking cessation at the population level

\section{WHAT THIS STUDY ADDS}

E-cigarette users in 2014-15 were more likely than non-users to make a quit attempt and succeed in quitting smoking

The overall rate of smoking cessation for the US population was significantly higher in 2014-15 (when e-cigarette use among smokers was high) than in 2010-11 (when e-cigarette use was very low), as well as than in all previous survey years (when e-cigarette use was practically non-existent)

E-cigarettes appear to have helped to increase smoking cessation at the population level cessation rate for $2014-15$ was significantly higher than that for $2010-11,5.6 \% \vee 4.5 \%(1.1 \%, 0.6 \%$ to $1.5 \%)$, and higher than those for all other survey years (range 4.3-4.5\%).

\section{CONCLUSION}

The substantial increase in e-cigarette use among US adult smokers was associated with a statistically significant increase in the smoking cessation rate at the population level. These findings need to be weighed carefully in regulatory policy making regarding e-cigarettes and in planning tobacco control interventions.

\section{Introduction}

Current regulatory policies on electronic cigarettes vary widely across countries. The United Kingdom provides a path for licensing e-cigarettes as a smoking cessation aid if they can pass safety standards and deliver nicotine like existing nicotine replacement therapy. ${ }^{1}$ In contrast, Australia bans the sale of e-cigarettes containing nicotine. ${ }^{2}$ US policy falls somewhere between. If there is no claim that e-cigarettes are a smoking cessation aid, they are treated as recreational products and regulated by the Tobacco Product Center of the Food and Drug Administration. Most manufacturers of e-cigarettes avoid making explicit claims on cessation benefits. ${ }^{34}$ Thus e-cigarettes are currently sold in the US with minor restrictions, as the most recent FDA rulings on e-cigarettes give grace periods for implementation of many components. ${ }^{5}$

The scientific community is also divided in its opinion of e-cigarettes as a smoking cessation aid. The debate is not as much about the potential efficacy of e-cigarettes for individual users as it is about the overall population impact. A recent Cochrane review suggests that e-cigarettes have a similar effect as nicotine replacement therapy for individual smokers who use them. ${ }^{6}$ Thus e-cigarettes will have a positive impact on the population cessation rate if they function as a nicotine replacement therapy and if they increase the total proportion of smokers using nicotine replacement products. $^{7-11}$ Others argue the overall impact of e-cigarettes on smoking in adults will be negative, even if they help some individuals to quit smoking. ${ }^{12}{ }^{13}$ The reason is that smokers who use e-cigarettes often use them occasionally, along with cigarettes. ${ }^{14}$ Such dual use could lessen the urgency to quit smoking, delaying the cessation process. If this is true, then the positive effect of e-cigarettes on some will be offset by the negative effect on many others, rendering the overall population impact as negative.

A randomized trial at the population level could resolve the debate, but such a trial is difficult to do. Instead, population studies have only compared 
smokers who have used e-cigarettes with those who have not. Some found that e-cigarette users quit at higher rates ${ }^{915}$ whereas others found the opposite. ${ }^{16-18}$ None has reported whether the overall population cessation rate (which includes both e-cigarette users and non-users) has changed because of e-cigarettes.

We examined the relation between e-cigarette use and smoking cessation in the US population using the largest representative sample of smokers and e-cigarette users available to date: the 2014-15 Current Population Survey-Tobacco Use Supplement (CPSTUS). Population surveys in the US began to measure e-cigarette use around 2010. ${ }^{14}$ The surveys found that most users were smokers. In 2010, about $1.4 \%$ of smokers were current users of e-cigarettes. ${ }^{19}$ Their usage among smokers increased dramatically by 2014 , with estimates from various studies ranging from 15\% to $30 \% .^{14} 19-21$ Thus a comparison between CPS-TUS 2010-11 and 2014-15 provides the best chance yet to examine the effect of e-cigarettes on the overall smoking cessation rate. We investigated two questions: First, did users of e-cigarettes in 2014-15 quit smoking at a higher rate than non-users? Second, did smokers in 2014-15 as a whole quit smoking at a higher rate than those in 2010-11? For a longer historical view, we also compared the 2014-15 survey with surveys earlier than 2010-11.

\section{Methods}

Data source

The US Current Population Survey-Tobacco Use Supplement (CPS-TUS) is a periodic tobacco survey attached to the Current Population Survey and administered by the US Census Bureau. It provides data from a nationally representative sample of US households of non-institutionalized civilians. Details of the design are published elsewhere. ${ }^{22}$ Our analysis included five surveys, 2001-02, 2003, 2006-07, 2010-11, and 2014-15. The sample sizes (excluding proxy respondents) were $185568,183810,172023$, 171365 , and 163920 , respectively. We did not include surveys earlier than 2001-02 because they did not assess quit attempts for all smokers.

\section{Participants}

For analysis of the prevalence of e-cigarette use in the 2014-15 survey, we included 161054 of the total sample of 163920 (we excluded those who did not answer questions on cigarettes or e-cigarettes). The analysis on smoking cessation included respondents aged 18 or older and who answered "every day" or "some days" to the question: "Around this time 12 months ago, were you smoking cigarettes every day, some days, or not at all?" Sample sizes for the five surveys for this analysis were 38999, 34440 , 31497,27280 , and 23270 , respectively. The rapidly declining sample size of eligible smokers over the years (as opposed to the change in total sample sizes for the surveys shown in the previous section) was largely a result of declining smoking prevalence over time. The smoking prevalence based on these surveys was, $21.0 \%, 18.9 \%, 18.5 \%, 16.1 \%$, and $13.7 \%$, for 2001-02, 2003, 2006-07, 2010-11, and 2014-15, respectively.

\section{Measures}

Current smokers were defined as having smoked at least 100 cigarettes in their lifetime and smoking every day or some days at the time of interview. A quit attempt was defined as having tried to quit smoking and achieving it for at least 24 hours. The "cessation rate" was the percentage of those who had quit for at least three months at the time of the interview among those who were smoking 12 months before the interview. $^{2324}$

Ever users of e-cigarettes were those who "ever used e-cigarettes, even one time." Before survey respondents were asked about their experience with e-cigarettes, they were first presented with the following description: "The next question is about electronic or e-cigarettes. You may also know them as vape-pens, hookah-pens, e-hookahs, or e-vaporizers. Some look like cigarettes and others look like pens or small pipes. These are battery-powered, usually contain liquid nicotine, and produce vapor instead of smoke."

Current users of e-cigarettes were ever users who answered "every day" or "some days" to the question: "Do you now use an e-cigarette every day, some days, or not at all?" Those who answered "not at all" were asked when they stopped using e-cigarettes. The "use of e-cigarettes" included any use within the past 12 months: those who reported currently using at the time of survey and those who reported using in the past 12 months but who had stopped by the time of survey.

\section{Analysis}

To compute quit attempt and cessation rate, we used those who reported smoking 12 months before the survey as the denominator. ${ }^{25}{ }^{26}$ All estimates were weighted using published weights for CPS-TUS, which accounted for demographic makeup of the sample and adjusted for non-response bias. ${ }^{22}$ The basic population weight controlled for age, race, sex, Hispanic origin, and individual state. The supplemental weight dealt with non-response. CPS-TUS collected data using both self report and proxy report. In the present study we used only the data from self report, treating proxy reported data as no response. The replicate weights were derived using balanced repeated replication. ${ }^{27}$ Each CPS-TUS conducted its survey in three waves; the response rate averaged over the waves for each survey was $64.0 \%, 63.6 \%, 62.0 \%, 61.2 \%$, and $54.2 \%$ for 2001-02, 2003, 2006-07, 2010-11, and 2014-15, respectively. ${ }^{28-32}$ We used $\chi^{2}$ tests or normal approximation to $\chi^{2}$ tests to compare independent proportions. To provide $95 \%$ confidence intervals we computed variances of point estimates using SASCallable SUDAAN, version $11 .^{33}$

\section{Results}

Table 1 shows the rates of ever use and current use of e-cigarettes in the 2014-15 survey by demographics. 


\begin{tabular}{|c|c|c|c|}
\hline \multirow[b]{2}{*}{ Characteristics } & \multirow[b]{2}{*}{ No of respondents } & \multicolumn{2}{|l|}{$\%(95 \% \mathrm{Cl})$} \\
\hline & & Ever users of e-cigarettes & Current users of e-cigarettes \\
\hline Overall & $161054^{*}$ & 8.5 (8.3 to 8.6$)$ & 2.4 (2.3 to 2.5$)$ \\
\hline \multicolumn{4}{|l|}{ Sex: } \\
\hline Male & 71881 & 9.6 (9.3 to 9.8$)$ & $2.6(2.5$ to 2.8$)$ \\
\hline Female & 89173 & $7.4(7.2$ to 7.7$)$ & 2.1 (2.0 to 2.2$)$ \\
\hline \multicolumn{4}{|l|}{ Age (years): } \\
\hline $18-24$ & 10667 & $14.6(13.8$ to 15.5$)$ & 3.4 (3.1 to 3.8$)$ \\
\hline $25-44$ & 52840 & $10.9(10.6$ to 11.3$)$ & $2.9(2.8$ to 3.1$)$ \\
\hline $45-64$ & 59246 & $7.0(6.8$ to 7.3$)$ & $2.2(2.1$ to 2.4$)$ \\
\hline$\geq 65$ & 38301 & $2.4(2.2$ to 2.6$)$ & $0.9(0.8$ to 1.0$)$ \\
\hline \multicolumn{4}{|l|}{ Ethnicity: } \\
\hline White & 117708 & $10.0(9.7$ to 10.2$)$ & 2.9 (2.7 to 3.0$)$ \\
\hline Hispanic & 16999 & $5.3(4.9$ to 5.7$)$ & $1.2(1.0$ to 1.4$)$ \\
\hline Black & 16045 & $5.1(4.7$ to 5.6$)$ & $1.3(1.1$ to 1.6$)$ \\
\hline Asian & 6343 & $3.5(3.0$ to 4.1$)$ & 0.7 (0.5 to 1.0) \\
\hline American Indian & 1537 & $12.2(9.9$ to 14.8$)$ & $3.4(2.4$ to 4.9$)$ \\
\hline Pacific Islander & 477 & $9.4(6.2$ to 14.0$)$ & 3.7 (1.9 to 7.2$)$ \\
\hline Other & 1945 & 19.8 (17.5 to 22.2$)$ & $6.5(5.2$ to 8.2$)$ \\
\hline \multicolumn{4}{|l|}{ Education: } \\
\hline$<12$ years & 14047 & $8.3(7.7$ to 8.9$)$ & $2.4(2.1$ to 2.7$)$ \\
\hline 12 years or GED & 47532 & 10.1 (9.8 to 10.5$)$ & $3.0(2.8$ to 3.1$)$ \\
\hline Some college & 46700 & $11.0(10.7$ to 11.4$)$ & $3.2(3.0$ to 3.4$)$ \\
\hline Bachelor degree or higher & 52775 & $4.6(4.4$ to 4.9$)$ & 1.1 (1.0 to 1.2$)$ \\
\hline
\end{tabular}

Overall, 8.5\% of US adults ( $\mathrm{n}=161054)$ had ever tried e-cigarettes and $2.4 \%$ were currently using them. Men were more likely to use e-cigarettes than women, and younger groups were more likely than older groups. The prevalence also differed by ethnicity and education.

Table 2 shows e-cigarette use by cigarette smoking status. Of 161054 respondents to the 2014-15 survey, 104788 were never smokers, 22548 were current smokers, and 2136 recent quitters (those who quit for less than one year). Never smokers had the lowest rate for e-cigarette use: $2.0 \%$ had ever used them. Recent quitters had the highest ever use rate, $49.3 \%$, which was even higher than that of current smokers, $38.2 \%$.

Table 2 also shows the distribution of these ever e-cigarette users by subgroups. Overall, $28.0 \%$ of ever users $(n=13042)$ were current users; the rest had stopped. About $22.8 \%$ stopped within the year before the survey, $22.1 \%$ stopped for one year or more, and $27.2 \%$ gave no date. Again, recent quitters $(n=984)$ were most likely to have continued using e-cigarettes, $38.7 \%$. If they had stopped e-cigarettes, they also were most likely to have only stopped within a year, 30.4\%. Longer term former smokers had stopped e-cigarettes for a longer period. The more time since quitting smoking, the less likely respondents were to give a stopping date for e-cigarettes.

Table 3 shows the prevalence of current e-cigarette use. Only $0.3 \%$ of never smokers currently used e-cigarettes at the time of survey. Again, recent quitters had the highest prevalence, $19.0 \%$, even higher than that of current smokers, $11.5 \%$.

Table 3 also shows the distribution of these current users of e-cigarettes by subgroups. Overall, $33.7 \%$ of them were daily users. Former smokers were more likely than current smokers to be daily users, with the highest proportion, $72.7 \%$, in recent quitters.

Figure 1 compares those who had used e-cigarettes within one year with those who had not. The withinone-year users included those who reported currently using e-cigarettes at the time of survey and those who reported using e-cigarettes within the past 12 months but had stopped by the time of survey.

\begin{tabular}{|c|c|c|c|c|c|c|c|}
\hline \multirow[b]{2}{*}{ Smoking status } & \multicolumn{2}{|c|}{ Prevalence of ever use of e-cigarettes } & \multicolumn{5}{|c|}{ Distribution of ever users of e-cigarettes } \\
\hline & $\begin{array}{l}\text { No of } \\
\text { respondents }\end{array}$ & $\%(95 \% \mathrm{Cl})$ & $\begin{array}{l}\text { No of } \\
\text { respondents }\end{array}$ & $\begin{array}{l}\% \text { current users } \\
(95 \% \mathrm{Cl})\end{array}$ & $\begin{array}{l}\% \text { stopped, }<1 \text { year } \\
(95 \% \mathrm{Cl})\end{array}$ & $\begin{array}{l}\% \text { stopped, } \\
\geq 1 \text { year }(95 \% \mathrm{Cl})\end{array}$ & $\begin{array}{l}\% \text { stopped, date } \\
\text { unknown }(95 \% \mathrm{Cl})\end{array}$ \\
\hline Never smoker & 104788 & 2.0 (1.8 to 2.1$)$ & 1547 & 14.9 (13.0 to 17.0$)$ & 18.2 (15.8 to 20.8$)$ & $22.8(20.3$ to 25.5$)$ & $44.2(40.6$ to 47.9$)$ \\
\hline \multicolumn{8}{|l|}{ Former smoker (years): } \\
\hline$>5$ & 25331 & $2.3(2.1$ to 2.6$)$ & 552 & 16.2 (12.7 to 20.4) & $7.6(5.1$ to 11.0$)$ & 36.8 (31.6 to 42.2$)$ & $39.5(35.1$ to 44.2$)$ \\
\hline $3-5$ & 3594 & 18.6 (17.0 to 20.2$)$ & 633 & $24.2(20.4$ to 28.4$)$ & $5.0(3.3$ to 7.5$)$ & 48.7 (44.1 to 53.2) & $22.2(18.3$ to 26.7$)$ \\
\hline $1-2$ & 2657 & 36.8 (34.8 to 38.8) & 967 & 35.8 (31.9 to 40.0) & 9.5 (7.4 to 12.0$)$ & $38.3(34.5$ to 42.4$)$ & 16.4 (13.6 to 19.7$)$ \\
\hline Recent quitter, «1 year & 2136 & $49.3(46.6$ to 52.0$)$ & 984 & 38.7 (35.1 to 42.3) & 30.4 (26.8 to 34.2$)$ & 13.1 (10.7 to 15.9$)$ & $17.9(15.2$ to 21.0$)$ \\
\hline Current smoker & 22548 & $38.2(37.4$ to 39.1$)$ & 8359 & 30.1 (29.0 to 31.3) & 26.8 (25.7 to 28.0$)$ & $18.3(17.3$ to 19.3$)$ & $24.8(23.5$ to 26.0$)$ \\
\hline Total & 161054 & $8.5(8.3$ to 8.6$)$ & 13042 & $28.0(27.1$ to 28.8$)$ & $22.8(21.9$ to 23.7$)$ & $22.1(21.2$ to 23.1$)$ & $27.2(26.2$ to 28.2$)$ \\
\hline
\end{tabular}

All percentages were weighted by population weights. 


\begin{tabular}{|c|c|c|c|c|c|}
\hline \multirow{2}{*}{ Smoking status } & \multicolumn{2}{|c|}{ Prevalence of current use of e-cigarettes } & \multicolumn{3}{|c|}{ Distribution of current users of e-cigarettes } \\
\hline & No of respondents & $\%(95 \% \mathrm{Cl})$ & No of respondents & Daily/current, \% $(95 \% \mathrm{Cl})$ & Non-daily/current, $\%(95 \% \mathrm{Cl})$ \\
\hline Never smoker & 104784 & $0.3(0.3$ to 0.3$)$ & 247 & $18.0(12.3$ to 25.6$)$ & $82.0(74.4$ to 87.7$)$ \\
\hline \multicolumn{6}{|l|}{ Former smoker (years): } \\
\hline$>5$ & 25331 & $0.4(0.3$ to 0.5$)$ & 87 & 47.5 (36.4 to 58.8$)$ & $52.5(41.2$ to 63.6$)$ \\
\hline $3-5$ & 3593 & $4.5(3.8$ to 5.3$)$ & 168 & $61.8(54.3$ to 68.8$)$ & $38.2(31.2$ to 45.7$)$ \\
\hline $1-2$ & 2655 & $13.2(11.5$ to 15.0$)$ & 347 & $64.7(58.5$ to 70.6$)$ & $35.3(29.5$ to 41.6$)$ \\
\hline Recent quitter, $<1$ year & 2133 & $19.0(17.1$ to 21.1$)$ & 383 & $72.7(67.3$ to 77.5$)$ & $27.3(22.5$ to 32.7$)$ \\
\hline Current smoker & 22531 & 11.5 (11.0 to 12.0$)$ & 2535 & 22.9 (20.9 to 25.2$)$ & $77.1(74.8$ to 79.1$)$ \\
\hline Total & $161027^{*}$ & $2.4(2.3$ to 2.5$)$ & 3767 & 33.7 (31.7 to 35.8$)$ & $66.3(64.3$ to 68.3$)$ \\
\hline
\end{tabular}

The top panel of figure 1 shows that within-oneyear users were more likely to have made an attempt to quit smoking in the previous 12 months than all the other three subgroups: ever users who had stopped e-cigarettes for one year or more, ever users who stopped e-cigarettes but did not give dates, and never users. The attempt rates were $65.1 \%, 48.4 \%, 48.8 \%$, and $37.8 \%$, respectively.

The bottom panel of figure 1 shows the annual cessation rate for these four subgroups. The cessation rates follow the pattern of quit attempts: $8.2 \%, 5.4 \%$, $5.3 \%$, and $4.6 \%$, respectively.

Figure 2 compares the results of 2014-15 with those of 2010-11, and with the three other surveys. The top panel shows that the overall quit attempt rate changed little until 2014-15: 40.3\%, 40.5\%, 39.9\%, 41.4\%, and $45.9 \%$, respectively. Using the 2001-02 survey as a reference, the 2010-11 and 2014-15 surveys had statistically higher quit attempt rates $(\mathrm{P}<0.05$ and $\mathrm{P}<0.001)$.
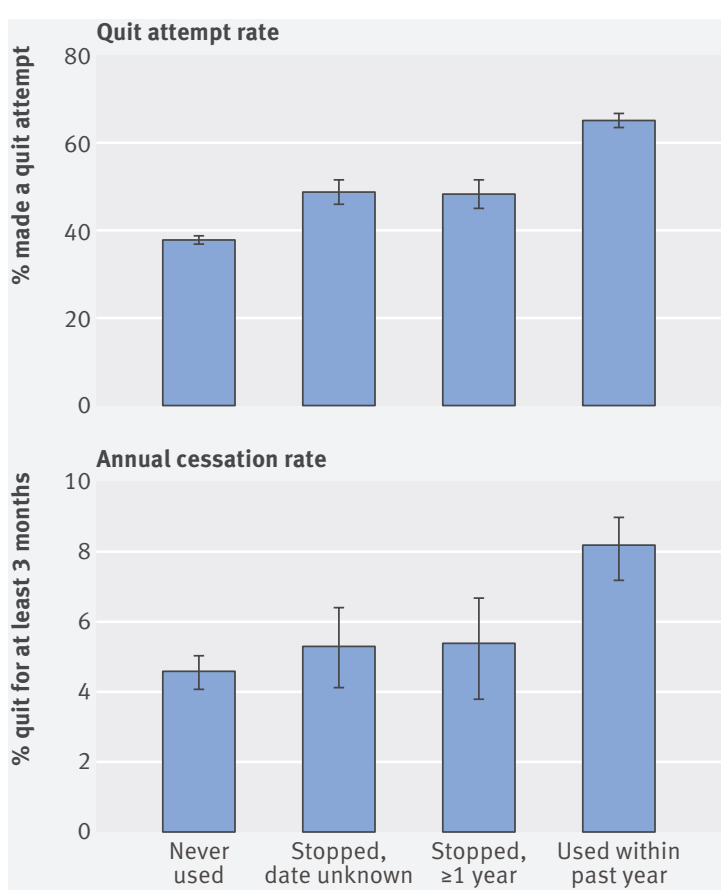

Fig 1 Q Quit attempt rate and annual cessation rate by e-cigarette use status, 2014-15, USA. CPS-TUS=Current Population Survey-Tobacco Use Supplement
The attemptratein the 2014-15 survey was noticeably higher. For ease of comparison, we combined the results for the three groups that did not use e-cigarettes in the past year (see fig 1) into one group (fig 2). The last two bars show that quit attempts for smokers who did not use e-cigarettes within one year $(40.1 \%)$ were similar to those in previous surveys. Quit attempts for e-cigarette users were, however, statistically significantly higher than for non-users., Numerically speaking, it was this e-cigarette user subgroup that raised the overall quit attempt rate for 2014-15, and thus the rate was statistically significantly higher than in all previous survey years.

The bottom panel of figure 2 shows the annual cessation rate, which follows the pattern of the quit attempt rate. The annual cessation rates did not change much until 2014-15: 4.3\%, 4.3\%, 4.5\%, 4.5\%, and $5.6 \%$ for $2001-02,2003,2006-07,2010-11$, and
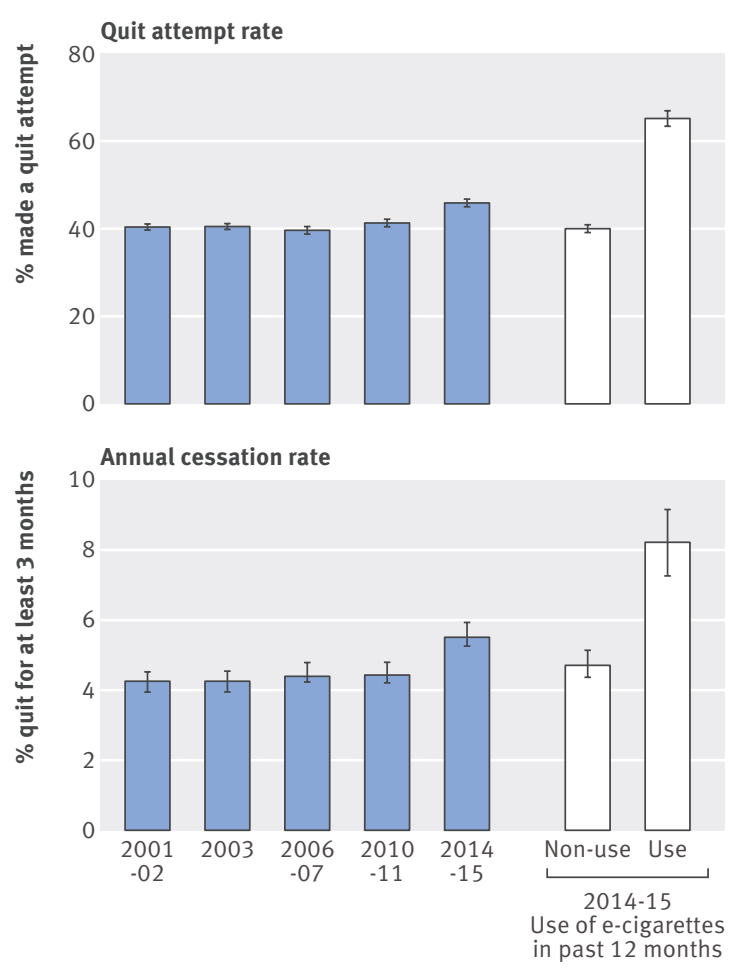

Fig 2 Quit attempt rate and annual cessation rate from 2001-02 to 2014-15, USA. CPS-TUS=Current Population Survey-Tobacco Use Supplement 
2014-15, respectively. Using 2001-02 as a reference, only 2014-15 had a statistically higher overall cessation rate $(\mathrm{P}<0.001)$. Compared with $2010-11,2014-15$ had a statistically significantly higher cessation rate, 5.6\% $v 4.5 \%$ (change $=1.1 \%, 95 \%$ confidence interval $0.6 \%$ to $1.5 \%$ ). Again, the $2014-15$ survey had a noticeably higher overall cessation rate because the e-cigarette user subgroup had a higher cessation rate than those who did not report e-cigarette use in the past year $(8.2 \%$ v $4.8 \%$, respectively, $(\mathrm{P}<0.001)$. The absolute difference of $3.5 \%$ (rounded from 3.48) translates into a $73 \%$ relative increase.

\section{Discussion}

This study has two principal findings. First, in 201415, e-cigarette users in the United States attempted to quit cigarette smoking and succeeded in quitting at higher rates than non-users. Second, the overall population smoking cessation rate in 2014-15 increased statistically significantly from that in 201011. The 1.1 percentage point increase in cessation rate (from $4.5 \%$ to $5.6 \%$ ) might appear small, but it represents approximately 350000 additional US smokers who quit in 2014-15.

\section{Strengths and limitations of this study}

The main strength of our study is that we used the largest representative sample of e-cigarette users among the US population. Moreover, by using the ongoing US Current Population Surveys, we evaluated the impact of e-cigarettes in a larger context through comparing the quit rate in 2014-15 with that of the same population survey from previous years. This provides the clearest result to date that e-cigarette use is not only associated with a higher smoking cessation rate at the individual user level but also at the population level.

Our study has limitations common to population surveys. Self report is subject to recall biases. Survey questions were limited, preventing more detailed analysis of the quitting process. For example, the lack of information on pharmacotherapy use in this survey prevents comparisons between e-cigarette users and those who use traditional pharmacotherapy. Though another national survey in 2014 found that more smokers in the US used e-cigarettes than FDA approved pharmacotherapy, ${ }^{34}$ similar to results from England, ${ }^{11}$ the inability to compare these two subgroups in the present survey is a limitation. Also, lack of information on the type of e-cigarette product used (ie, open versus closed system) limits further comparison to other population studies of e-cigarettes that might have been informative.

Another limitation is that this study is not a randomized trial at the population level. Thus it is important to examine other possible influences on the population smoking cessation rate. We discuss two major interventions that occurred at the national level and took place around the 2010-11 and 2014-15 surveys.

First, in 2009 there was an increase in federal tobacco tax. ${ }^{35}$ The national cigarette tax increased by
$158 \%$, resulting in an immediate reduction in cigarette uptake among US adolescents. ${ }^{35}$ In our study we found a small but statistically significant increase in quit attempts among US adults, from $39.9 \%$ in 200607 to $41.4 \%$ in $2010-11$ (fig 2, top panel). However, the total cessation rate did not change: $4.5 \%$ for both surveys (fig 2, bottom panel). Thus the effect of the 2009 federal tax on quitting by adult smokers, if there was an immediate one, was no longer detectable by 2010-11. This lack of change in smoking cessation under such a dramatic tax increase accentuates the difficulty in improving quit rates at the population level. ${ }^{23}$ It does provide a reference point to evaluate the magnitude of change reported for the 2014-15 US Current Population Survey-Tobacco Use Supplement (CPS-TUS).

Second, since 2012 there have been annual, national media campaigns aimed at increasing quit rates among adult smokers. ${ }^{36}$ The TIPS from Former Smokers campaign used evocative television spots showing the serious health consequences of tobacco use. This campaign, running from nine to 20 weeks in any given year, reached a large segment of the smoking population. A national survey after the first round of the campaign found that $78 \%$ of smokers saw at least one media spot. ${ }^{37}$ By 2015, there had been four rounds of the campaign. Surveys found a statistically significant increase in quit attempts, and the cessation rate of those who made a quit attempt was estimated to be between $5.7 \%$ and $6.1 \% .^{3637}$

In the present study we found statistically significant increases in both quit attempt and cessation rates from 2010-11 to 2014-15. This period coincided with the TIPS campaign and the dramatic increase in e-cigarette use. ${ }^{36}$

Could TIPS alone explain the increase? Given the reach of the first TIPS campaign, after four rounds it was expected to reach most US smokers by 2014-15. ${ }^{36}$ ${ }^{37}$ However, the majority of smokers did not appear to change their quitting behavior: smokers who did not use e-cigarettes were the majority (77\%) in 2014-15. Neither their attempt rate nor the annual cessation rate was statistically different from that of all smokers in 2010-11 (fig 2). It was e-cigarette users in 2014-15 who showed a dramatically higher quit attempt rate and a higher cessation rate. Thus it would be unlikely that the TIPS campaign was solely responsible for the overall increase because that would mean the TIPS messages only resonated with those who happened to use e-cigarettes in 2014-15.

Given that the e-cigarette user subgroup was the only group that had statistically significantly higher rates in 2014-15 (fig 2), it is tempting to attribute the increase in the overall smoking cessation rate in 2014-15 solely to e-cigarette use. However, e-cigarette use itself could be an indicator of motivation to quit smoking, which would predict a higher quit rate. ${ }^{34}$ Thus, attributing the full $73 \%$ relative difference to e-cigarettes is likely an overestimate of their effect.

What is more probable is that e-cigarettes and tobacco control measures, such as the TIPS campaign 
and other state level activities for tobacco control, worked synergistically to produce the first substantial increase in population cessation in the US in the past 15 years (fig 2): tobacco control campaigns increased smokers' desire to quit, and e-cigarettes increased the probability of motivated smokers making a quit attempt and staying abstinent. Viewed from the context of an earlier analysis that examined the US population data from 1991 onward, ${ }^{23}$ this is the first time in almost a quarter of a century that the smoking cessation rate in the US has increased at the population level.

\section{Comparison with other studies}

The results from our study agree with some studies and differ from others. ${ }^{911} 15-18$ Our study supports a report from England where e-cigarette use was found to be associated with a higher success rate of quit attempts. ${ }^{11}$ More importantly, we found that e-cigarette use was also associated with a higher quit attempt rate, which eventually translates into a higher overall population cessation rate. ${ }^{23}$

The study differs from some other studies that compared e-cigarette users with non-users and found a negative correlation between e-cigarette use and smoking cessation. The key difference seems to be related to the difference in timing of data collection for this study compared with that of earlier studies. ${ }^{16} 1838$

First, as e-cigarettes grew more popular over time, more people used them intensively. ${ }^{14}$ This study found that $33.7 \%$ of current e-cigarette users were daily users. Earlier studies rarely reported on intensity of usage. ${ }^{13}$ Many did not report if e-cigarettes were used within the past 12 months, but only identified the users as ever users. ${ }^{13}$ Intensive use of e-cigarettes is key to their potential effect as a smoking cessation aid. ${ }^{14} 1534$ Our study, based on the largest representative sample of e-cigarette users in the US in 2014-15, found that more than $70 \%$ of recent quitters who used e-cigarettes were still using e-cigarettes daily. The daily use might have been critical in preventing relapse.

Second, e-cigarette products have evolved, and open system devices have become more popular. ${ }^{39}$ Open systems generally deliver a greater concentration of nicotine and engender a higher level of perceived control than do closed systems. ${ }^{39} 40$ The use of open systems was associated with higher smoking cessation rates. ${ }^{40-42}$ Thus if the proportion of open system users increases, it may lead to higher quit rates for all e-cigarette users.

A more important finding from this study that differs from previous studies is that the increased smoking cessation rate among e-cigarette users translated into a higher overall population cessation rate in 201415, compared with 2010-11. If the overall population cessation rate did not increase in 2014-15, then the meaning of the subgroup difference between e-cigarette users and non-users would be less clear. The use of e-cigarettes was not a randomly assigned condition but rather self selected by smokers. Such a self selection process could result in no change in the overall population rate, even if there are subgroups differences. In fact, one of the most vexing results in the smoking cessation literature is that the population cessation rate in the US has shown no discernible trend from 1991 to 2010, even though an increasing proportion of smokers used proven pharmacotherapy. ${ }^{23}$ During the two decades before 2011, the annual cessation rate hovered around $4.4 \% .^{23}$ Our study replicated this finding in the first four CPS-TUSs in the 21st century. From 2001-02 to 2010-11, the cessation rate ranged from $4.3 \%$ to $4.5 \%$. It was in $2014-15$ CPSTUS, where we found the first statistically significant increase in the population cessation rate (fig 2).

With an increase in the overall population cessation rate as context, the subgroup difference between e-cigarette users and non-users found in this study takes on more importance. The cessation rate for those who did not use e-cigarettes in 2014-15 CPSTUS remained statistically indistinguishable from those of the previous years (see fig 2). It was the e-cigarette users who quit at a clearly higher rate $(8.2 \%)$ that brought the overall population cessation rate to a higher level. Such a data pattern makes it more reasonable to conclude that e-cigarette use contributes to the increase in the overall smoking cessation rate.

Our study replicates other US studies on the ethnic representation of e-cigarette use. ${ }^{1920}$ E-cigarette use is observed across all ethnic groups, but rates are higher for some groups. ${ }^{1920}$ Our study focuses its analysis on the overall population effect of e-cigarette on smoking cessation in adults in the US context. Future studies might examine the e-cigarette effect by demographic subgroups. The main results, based on the diverse US population, suggest a similar effect may be observed in other jurisdictions if a sufficient proportion of smokers use e-cigarettes on a daily basis as aids to quit smoking.

\section{Conclusion and policy implications}

This study, based on the largest representative sample of e-cigarette users to date, provides a strong case that e-cigarette use was associated with an increase in smoking cessation at the population level. We found that e-cigarette use was associated with an increased smoking cessation rate at the level of subgroup analysis and at the overall population level. It is remarkable, considering that this is the kind of data pattern that has been predicted but not observed at the population level for cessation medication, such as nicotine replacement therapy and varenicline. ${ }^{2325264344}$ This is the first statistically significant increase observed in population smoking cessation among US adults in the past 15 years. ${ }^{23}$ These findings need to be weighed carefully in regulatory policy making and in the planning of tobacco control interventions. ${ }^{45}$

We thank Jessica Sun for her comments on earlier drafts of the paper and for her help in preparing the manuscript.

Contributors: S-HZ and Y-LZ conceived the study. Y-LZ, S-HZ, and SW analyzed the data. S-HZ, Y-LZ, SW, SEC, and GJT interpreted the data. S-HZ, Y-LZ, SEC, GJT, and SW helped draft the manuscript. All authors had full access to all of the data in the study and take responsibility for the integrity of the data and the accuracy of the data analysis. S-HZ is guarantor for the study. 
Funding: This study was supported by the National Cancer Institute of the National Institutes of Health under the State and Community Tobacco Control (SCTC) Initiative (award No U01CA154280). The content is solely the responsibility of the authors and does not necessarily represent the official views of the National Institutes of Health. Funders of this study had no role in the study design; collection, analysis, and interpretation of the data; writing of the manuscript; or decision to submit the manuscript for publication. Competing interests: All authors have completed the ICMJE uniform disclosure form at www.icmje.org/coi_disclosure.pdf and declare: $\mathrm{S}-\mathrm{HZ}$ has received a grant from the National Institutes of Health for this work. All authors declare no financial relationships with any organizations that might have an interest in the submitted work in the previous three years; and no other relationships or activities exist that could appear to have influenced the submitted work.

Ethical approval: This study is a secondary data analysis of publicly available data, approved by the UCSD Human Research Protection Program (institutional review board No 140821).

Data sharing: The full dataset is publicly available from the US Census Bureau.

Transparency: The lead author (S-HZ) affirms that the manuscript is an honest, accurate, and transparent account of the study being reported; that no important aspects of the study have been omitted; and that any discrepancies from the study as planned have been explained.

This is an Open Access article distributed in accordance with the Creative Commons Attribution Non Commercial (CC BY-NC 4.0) license, which permits others to distribute, remix, adapt, build upon this work non-commercially, and license their derivative works on different terms, provided the original work is properly cited and the use is noncommercial. See: http://creativecommons.org/licenses/by-nc/4.0/.

1 Medicines and Healthcare Products Regulatory Agency. Licensing Procedure for Electronic Cigarettes and Other Nicotine Containing Products (NCPs) as Medicines. https://www.gov.uk/government/ uploads/system/uploads/attachment_data/file/595533/Licensing_ procedure for electronic cigarettes and other nicotine contain products_as_medicines.pdf. Published 2017. Accessed July 7, 2017.

2 Douglas H, Hall W, Gartner C. E-cigarettes and the law in Australia. Aust Fam Physician 2015;44:415-8.s

3 Zhu S-H, Sun JY, Bonnevie E. Four hundred and sixty brands of e-cigarettes and counting: implications for product regulation. Tob Control 2014;23(Suppl 3):iii3-9. doi:10.1136/ tobaccocontrol-2014-051670.

4 Ramamurthi D, Gall PA, Ayoub N, Jackler RK. Leading-brand advertisement of quitting smoking benefits for e-cigarettes. Am J Public Health 2016;106:2057-63. doi:10.2105/ AJPH.2016.303437.

5 Food and Drug Administration, HHS. Deeming Tobacco Products To Be Subject to the Federal Food, Drug, and Cosmetic Act, as Amended by the Family Smoking Prevention and Tobacco Control Act; Restrictions on the Sale and Distribution of Tobacco Products and Required Warning Statements for Tobacco Products. Final rule. Fed Regist 2016;81:28973-9106.

6 Hartmann-Boyce J, McRobbie H, Bullen C, Begh R, Stead LF, Hajek P. Electronic cigarettes for smoking cessation. In: Cochrane Database of Systematic Reviews. John Wiley \& Sons, Ltd, 2016, http:// onlinelibrary.wiley.com/doi/10.1002/14651858.CD010216.pub3/ abstract, Accessed September 14, 2016 doi:10.1002/14651858. CD010216.pub3.

7 Levy DT, Cummings KM, Villanti AC. A framework for evaluating the public health impact of e-cigarettes and other vaporized nicotine products. Addiction 2017;112:8-17. doi:10.1111/add.13394.

8 Etter J-F. E-cigarettes: methodological and ideological issues and research priorities. BMC Med 2015;13:32. doi:10.1186/s12916014-0264-5.

9 Brown J, Beard E, Kotz D, Michie S, West R. Real-world effectiveness of e-cigarettes when used to aid smoking cessation: a cross-sectional population study. Addiction 2014;109:1531-40. doi:10.1111/ add.12623.

10 Farsalinos KE, Poulas K, Voudris V, Le Houezec J. Electronic cigarette use in the European Union: analysis of a representative sample of 27460 Europeans from 28 countries. Addiction 2016;111:2032-40. doi:10.1111/add.13506.

11 Beard E, West R, Michie S, Brown J. Association between electronic cigarette use and changes in quit attempts, success of quit attempts, use of smoking cessation pharmacotherapy, and use of stop smoking services in England: time series analysis of population trends. BM 2016;354:i4645. doi:10.1136/bmj.i4645

12 Chapman S. E-cigarettes: the best and the worst case scenarios for public health-an essay by Simon Chapman. BMJ 2014;349:g5512. doi:10.1136/bmj.g5512.
13 Kalkhoran S, Glantz SA. E-cigarettes and smoking cessation in real-world and clinical settings: a systematic review and metaanalysis. Lancet Respir Med 2016;4:116-28. doi:10.1016/S22132600(15)00521-4.

14 Glasser AM, Collins L, Pearson JL. Overview of electronic nicotine delivery systems: a systematic review. Am J Prev Med 2017;52:e3366. doi:10.1016/j.amepre.2016.10.036

15 Biener L, Hargraves JL. A longitudinal study of electronic cigarette use among a population-based sample of adult smokers: association with smoking cessation and motivation to quit. Nicotine Tob Res 2015; 17:127-33. doi:10.1093/ntr/ntu200.

16 Christensen T, Welsh E, Faseru B. Profile of e-cigarette use and its relationship with cigarette quit attempts and abstinence in Kansas adults. Prev Med 2014;69:90-4. doi:10.1016/ j.ypmed.2014.09.005.

17 Al-Delaimy WK, Myers MG, Leas EC, Strong DR, Hofstetter CR. E-cigarette use in the past and quitting behavior in the future: a population-based study. Am J Public Health 2015;105:1213-9. doi:10.2105/AJPH.2014.302482.

18 Shi Y, Pierce JP, White M. E-cigarette use and smoking reduction or cessation in the 2010/2011 TUS-CPS longitudinal cohort. BMC Public Health 2016;16:1105. doi:10.1186/s12889-016-3770-x.

19 McMillen RC, Gottlieb MA, Shaefer RMW, Winickoff JP, Klein JD. Trends in electronic cigarette use among U.S. adults: use is increasing in both smokers and nonsmokers. Nicotine Tob Res 2015;17:1195202. doi:10.1093/ntr/ntu213.

20 Delnevo CD, Giovenco DP, Steinberg MB. Patterns of electronic cigarette use among adults in the United States. Nicotine Tob Res 2016:18:715-9. doi:10.1093/ntr/ntv237.

21 Schoenborn CA, Gindi RM. Electronic cigarette use among adults: United States, 2014. NCHS Data Brief 2015;217:1-8

22 United States Census Bureau, National Cancer Institute, Food and Drug Administration. Tobacco Use Supplement to the Current Population Survey (TUS-CPS). https://cancercontrol.cancer.gov/brp/ tcrb/tus-cps/. Published 2016. Accessed December 9, 2016.

23 Zhu S-H, Lee M, Zhuang Y-L, Gamst A, Wolfson T. Interventions to increase smoking cessation at the population level: how much progress has been made in the last two decades?Tob Control 2012;21:110-8. doi:10.1136/tobaccocontrol-2011-050371.

24 Gilpin EA, Pierce JP, Farkas AJ. Duration of smoking abstinence and success in quitting. J Natl Cancer Inst 1997;89:572-6. doi:10.1093/ jnci/89.8.572

25 Pierce JP, Gilpin EA. Impact of over-the-counter sales on effectiveness of pharmaceutical aids for smoking cessation. JAMA 2002;288:1260-4. doi:10.1001/jama.288.10.1260.

26 Zhu S-H, Cummins SE, Gamst AC, Wong S, Ikeda T. Quitting smoking before and after varenicline: a population study based on two representative samples of US smokers. Tob Control 2016;25:464-9. doi:10.1136/tobaccocontrol-2015-052332.

27 Davis WW, Hartman AM, Gibson JT. Trends in smoking prevalence by race based on the Tobacco Use Supplement to the Current Population Survey. https://s3.amazonaws.com/sitesusa/wp-content/uploads/ sites/242/2014/05/2007FCSM Davis-VII-C.pdf. Published 2015. Accessed July 3, 2017

28 US Department of Commerce. Census Bureau. National Cancer Institute and Centers for Disease Control and Prevention Cosponsored Tobacco Use Supplement to the Current Population Survey (2001-2002). Technical Documentation. https://www.census.gov/ programs-surveys/cps/technical-documentation/complete.html. Published 2004. Accessed July 3, 2017.

29 US Department of Commerce. Census Bureau. National Cancer Institute and Centers for Disease Control and Prevention Cosponsored Tobacco Use Special Cessation Supplement to the Current Population Survey (2003). Technical Documentation. https://cancercontrol.cancer.gov/brp/tcrb/tus-cps/info.html. Published 2006. Accessed July 3, 2017.

30 US Department of Commerce. Census Bureau. National Cancer Institute and Centers for Disease Control and Prevention Co-sponsored Tobacco Use Supplement to the Current Population Survey (2006-07). Technical Documentation. https://cancercontrol.cancer.gov/brp/tcrb/ tus-cps/citation.html. Published 2008. Accessed July 3, 2017.

31 US Department of Commerce. Census Bureau. National Cance Institute-sponsored Tobacco Use Supplement to the Current Population Survey (2010-11) Technical Documentation. https:// www.census.gov/programs-surveys/cps/technical-documentation/ complete.html. Published 2012. Accessed July 3, 2017.

32 US Department of Commerce. Census Bureau. National Cancer Institute and Food and Drug Administration co-sponsored Tobacco Use Supplement to the Current Population (2014-15). Technical Documentation. https://www.census.gov/programs-surveys/cps/ technical-documentation/complete.html. Published 2016. Accessed July 3, 2017.

33 Research Triangle Institute. Release 11.Vol 1 and 2, Research Triangle Park, NC, Research Triangle Institute, 2012. (SUDAAN Language Manual.). 
34 Zhuang Y-L, Cummins SE, Y Sun J, Zhu S-H. Long-term e-cigarette use and smoking cessation: a longitudinal study with US population. Tob Control 2016;25(Suppl 1):i90-5. doi:10.1136 tobaccocontrol-2016-053096.

35 Huang J, Chaloupka FJ. The Impact of the 2009 Federal Tobacco Excise Tax Increase on Youth Tobacco Use. NBER Working Paper No. 18026. National Bureau of Economic Research; 2012. http://www. nber.org/papers/w18026. Accessed December 16, 2016.

36 Neff LI, Patel D, Davis K, Ridgeway W, Shafer P, Cox S. Evaluation of the national Tips From Former Smokers campaign: the 2014 longitudinal cohort. Prev Chronic Dis 2016;13:E42. doi:10.5888/pcd13.150556.

37 McAfee T, Davis KC, Alexander RL Jr, Pechacek TF, Bunnell R. Effect of the first federally funded US antismoking national media campaign. Lancet 2013;382:2003-11. doi:10.1016/S0140-6736(13)61686-4.

38 Pearson JL, Stanton CA, Cha S, Niaura RS, Luta G, Graham AL. E-Cigarettes and Smoking Cessation: Insights and Cautions From a Secondary Analysis of Data From a Study of Online Treatment-Seeking Smokers. Nicotine Tob Res 2015;17:1219-27. doi:10.1093/ntr/ntu269.

39 Farsalinos KE, Spyrou A, Tsimopoulou K, Stefopoulos C, Romagna $\mathrm{G}$, Voudris V. Nicotine absorption from electronic cigarette use: comparison between first and new-generation devices. Sci Rep 2014:4:4133. doi:10.1038/srep04133.
40 Hitchman SC, Brose LS, Brown J, Robson D, McNeill A. Associations between e-cigarette type, frequency of use, and quitting smoking: findings from a longitudinal online panel survey in Great Britain. Nicotine Tob Res 2015;17:1187-94. doi:10.1093/ntr/ ntv078.

41 Chen C, Zhuang Y-L, Zhu S-H. E-cigarette design preference and smoking cessation: a U.S. population study. Am J Prev Med 2016;51:356-63. doi:10.1016/j.amepre.2016.02.002.

42 Malas M, van der Tempel J, Schwartz R. Electronic Cigarettes for Smoking Cessation: A Systematic Review. Nicotine Tob Res 2016;18:1926-36. doi:10.1093/ntr/ntw119.

43 West R, DiMarino ME, Gitchell I, McNeill A. Impact of UK policy initiatives on use of medicines to aid smoking cessation. Tob Control 2005;14:166-71. doi:10.1136/tc.2004.008649.

44 Shiffman S, Gitchell J, Pinney JM, Burton SL, Kemper KE, Lara EA. Public health benefit of over-the-counter nicotine medications. Tob Control 1997;6:306-10. doi:10.1136/tc.6.4.306.

45 Yong $\mathrm{H}-\mathrm{H}$, Hitchman SC, Cummings KM. Does the regulatory environment for e-cigarettes influence the effectiveness of e-cigarettes for smoking cessation?: Longitudinal findings from the ITC Four Country Survey. Nicotine Tob Res 2017; [Published online 4 March.]. doi:10.1093/ntr/ntx056. 